\title{
Parental age at childbirth and children's educational outcomes: evidence from upper-secondary schools in Italy
}

\author{
Stefano Cantalini ${ }^{1}$, Raffaele Guetto ${ }^{2^{*}}$ (D) and Nazareno Panichella ${ }^{1}$
}

\footnotetext{
* Correspondence: raffaele.guetto@ unifi.it

${ }^{2}$ Department of Statistics, Computer Science, Applications, University of Florence, viale Morgagni 59, 50134 Florence, Italy

Full list of author information is available at the end of the article
}

\begin{abstract}
In the last decades, Western societies have been involved in huge demographic changes, amongst which one of the most important has been the increasing postponement of the transition to parenthood. This paper aims at analysing the consequences of later motherhood and fatherhood on children's participation in upper-secondary schools in Italy, considering both the vertical and horizontal dimensions of education. It also aims at highlighting the role of father-mother age difference and heterogeneity in the effects by parental SES and birth order. Using Italian labour force survey data (2005-2014), results show that late parenthood is positively associated with educational attainment, whereas teenage and early parenthood negatively affect children's educational outcomes, net of detailed information on parental SES. Age at parenthood affects the educational achievement mostly for children of low- and middle-educated parents, who are more penalized by early childbearing and more favoured by late parenthood than the offspring of the tertiary educated. Moreover, only children are less affected by age at parenthood, especially in comparison with later-born children. Finally, children's educational outcomes are worse when the mother is older than the father, independently from the educational outcome considered, whereas they are better in case of parental age homogamy or when the father is slightly older than the mother.
\end{abstract}

Keywords: Age at parenthood, Postponement, Early childbearing, Late parenthood, Inequalities of educational outcomes, Italy

\section{Introduction}

In the last decades, Western societies have been involved in huge demographic changes, amongst which one of the most important has been the increasing postponement of the transition to motherhood, which has partly been responsible also for the diffusion of low (and lowest-low) fertility rates in Europe (Kohler et al., 2002; Salvini, 2004). Similarly to other European countries (Billari et al., 2006), also in the Italian society women's prolonged permanence in the school system, starting from the cohorts born in the late 70 s, has been claimed to be the most important driver of the postponement of the transition to motherhood (Billari \& Rosina, 2004). In the early ‘70s, the average women’s age at first birth was approximately 25 throughout Western Europe, with relatively small differences

(c) The Author(s). 2020 Open Access This article is licensed under a Creative Commons Attribution 4.0 International License, which permits use, sharing, adaptation, distribution and reproduction in any medium or format, as long as you give appropriate credit to the original author(s) and the source, provide a link to the Creative Commons licence, and indicate if changes were made. The images or other third party material in this article are included in the article's Creative Commons licence, unless indicated otherwise in a credit line to the material. If material is not included in the article's Creative Commons licence and your intended use is not permitted by statutory regulation or exceeds the permitted use, you will need to obtain permission directly from the copyright holder. To view a copy of this licence, visit http://creativecommons.org/licenses/by/4.0/. 
across countries (Oláh, 2015). However, according to Eurostat data, in 2017 it increased to 31.1 in Italy, whereas the EU-28 average is 29.1 . The analysis of the social consequences of the increasing mother's age at childbirth is therefore a cutting-edge topic of research across social sciences. The analysis of the consequences of later motherhood for children, in particular, has been a subject of renewed interest also in light of contradictory theoretical arguments and empirical findings (Goisis \& Sigle-Rushton, 2014). In fact, whereas the medical literature tends to underline the adverse outcomes for both mothers and children for pregnancies amongst women aged more than 35 (see, e.g. Bewley et al., 2005), recent evidence in the socio-demographic literature shows that later motherhood is associated to better children's educational outcomes (Fall et al., 2015; Myrskylä et al., 2017).

The contribution of this paper is to analyse the association between mothers' age at childbirth and Italian children's participation in upper-secondary school, considering both the vertical (enrolment in a 5-year upper-secondary school) and the horizontal dimension (access to the most prestigious academic track, i.e. liceo classico and liceo scientifico) of the inequality of educational outcomes (IEO). The focus on upper-secondary education is important because, despite enrolments at upper-secondary schools have become almost universal, evidence suggests that the strong disadvantage of children of the lowest socioeconomic strata, compared to the most privileged ones, in the probability of academic track enrolment diminished only slightly in Italy (Panichella \& Triventi, 2014; Guetto \& Vergolini, 2017), a state of affairs similar to other European countries (Ichou \& Vallet, 2011; Schneider \& Tieben, 2011). Although IEO in upper-secondary schools in Italy has been extensively studied, there is no evidence on how it has been affected by the postponement of childbearing.

The empirical strategy adopted in this paper allows to identify the net association between mother's age at childbirth and offspring's educational outcomes-i.e. controlling for detailed information on parental socioeconomic status (SES). In addition, our empirical analyses take into account both parents' age at childbirth. At the very least, given the well-known age homogamy between partners, with a limited age difference in favour of the man (Shehan et al., 1991; Ní Bhrolcháin, 2005), controlling for paternal age at childbirth is necessary to obtain a more robust and unbiased estimate of the association between mother's age at childbirth and children's educational outcomes. Beyond this, although often neglected in the literature, paternal age at childbirth-as well as the father-mother age difference-is likely to have an independent effect, too.

In our work, we also investigate the possible existence of heterogeneity in the associations between parents' age at childbirth and children's outcomes, depending on the combination between parental SES and the specific educational outcome considered. In fact, the increasing delay in childbearing observed in all Western countries may reinforce the reproduction of IEO if the postponement of childbearing is more beneficial for children of the more advantaged individuals, an argument consistent with the diverging destinies thesis (DDT), which argues that family changes associated with the second demographic transition are leading to greater disparities in children's opportunities (McLanahan, 2004). Finally, how the associations vary by children's birth order is investigated, given the strong interconnection between parental age at childbirth and parity.

The paper is structured as follows. The 'Inequality in upper-secondary education in Italy' section discusses the main features of the Italian educational system at the uppersecondary level. The theoretical background is discussed in the 'Theoretical 
background' section, which starts with the 'Age at parenthood and children's educational outcomes' section concerning the medical and socio-demographic literature on the associations between both parents' age at childbirth and children's educational outcomes. Possible heterogeneity in those associations, by social background and birth order, is discussed in the 'Heterogeneity in the effects of age at parenthood: social origins and birth order' section, whereas our research hypotheses are outlined in the 'Research hypotheses' section. The 'Data, variables and methods' section describes the data and methods used for the analyses, and results are presented in the 'Empirical evidence' section. The 'Conclusion' section concludes the paper with a discussion of the main results.

\section{Inequality in upper-secondary education in Italy}

Parents usually decide whether to enrol their children to upper-secondary school when the latter are aged 14, at the end of lower secondary school. Starting from 2007, education in Italy has become compulsory up to 16 years of age; thus, nowadays, virtually all children should make the transition to upper-secondary school and attend a certain track up to 16 years of age. However, dropping out of school before the age of compulsory schooling is common in Italy. Data from the Ministry of Education for the school year 2013/2014 show a dropout rate of $2.3 \%$ and $4.4 \%$ at the lower-secondary and upper-secondary level, respectively. Dropout rates are particularly high during the first year of upper-secondary school (approximately 7\%). The proportions of students not admitted to the following grade are high as well, especially in the first and second years of upper-secondary school (16.3\% and $10.5 \%$, respectively).

When it comes to the horizontal dimension, the Italian upper-secondary school is stratified into three 5-year tracks characterised by different institutional purposes, subjects and prestige. First, the academic track includes the more prestigious and demanding liceo classico and liceo scientifico, as well as other-less prestigious-curricula focusing on foreign languages (liceo linguistico), arts (liceo artistico), music (liceo musicale e coreutico) and teaching-training schools (liceo psico-socio pedagogico and liceo delle scienze umane). Second, the technical track (istituti tecnici) provides theoretical and vocational education in the economic and technological fields. Third, the vocational track (istituti professionali) supplies vocational training in areas of the service, industry and craft sectors. ${ }^{1}$ Starting from the cohorts born in the 70 s, the proportion of students enrolled in the technical and vocational tracks has slightly but constantly decreased over time, whereas the number of enrolees in the academic track has substantially increased, with the exception of liceo classico (Guetto \& Vergolini, 2017).

Differently from other highly stratified educational systems such as the German one, students can enrol in whatever type of upper-secondary school regardless of previous performances, because there is no formal system of teachers' recommendations, which makes the role of the family of origin particularly important (Checchi \& Flabbi, 2007; Contini \& Scagni, 2011). Although all 5-year upper-secondary tracks allow university enrolment since 1969-when a reform 'liberalised' the access to university in Italy- the proportion of upper-secondary graduates enrolled in tertiary education changes

${ }^{1}$ Concerning enrolments in 5-year tracks, in the school year 2013/2014, 6.1\% of the pupils chose liceo classico, and $22.7 \%$ opted for liceo scientifico; $20.1 \%$ enroled in the remaining curricula of the academic track, whereas $31.2 \%$ chose the technical track and $19.9 \%$ the vocational track. 
strongly according to the track. For instance, in 2015 more than $90 \%$ of graduates from liceo classico and liceo scientifico had ever enrolled in university within 3 years after the completion of upper-secondary school, whereas the figures were approximately $40 \%$ and $20 \%$ for graduates from technical and vocational tracks (ISTAT, 2016). The attendance of the liceo classico and liceo scientifico is therefore crucial for the enrolment in tertiary education, making it to be an important factor that mediates the association between social origins and access to higher education (Ballarino \& Panichella, 2016).

\section{Theoretical background}

\section{Age at parenthood and children's educational outcomes}

Both medical and socio-demographic research agree on the negative association between early parental age at childbirth and children's health and educational outcomes. In this respect, a vast literature, especially focusing on Anglo-Saxon countries, where teenage births are more common (Singh et al., 2001), showed that teen parenting is negatively associated with many children's outcomes (Addo et al., 2016), notwithstanding the causality of this relation has been questioned once the socioeconomic background is taken into account (Levine et al., 2007). For instance, children born to adolescent or young mothers have an increased risk of low birth weight and preterm birth, stunting in infancy, short adult height, greater likelihood of experiencing early sexual debut, and fighting in school (Geronimus et al., 1994; Levine et al., 2001, 2007; Fall et al., 2015). They also reach lower levels of education, score significantly lower on measures of mathematics, reading recognition and comprehension, vocabulary test scores, and are more likely to repeat a grade (Cooksey, 1997; Hofferth \& Reid, 2002; Francesconi, 2008; Björklund \& Salvanes, 2011). This negative association can be explained not only by the reduction of young mothers' investment in human capital because of early parenthood (Martin, 2000) but also by their lower maturity at childbearing and their lack of parenting skills (Levine et al., 2007), which in turn affect their children's outcomes.

Less agreement between medical and socio-demographic research regards those births from parents aged 35 and above. The increasing postponement of the transition to parenthood in Western countries has been the cause of concern in the medical literature, which underlines many adverse outcomes for both parents and children if births occur at relatively old ages (Bewley et al., 2005). Indeed, postponement of childbearing may have important health and well-being consequences for offspring and their parents. For example, the risk of negative birth and childhood outcomes-e.g. miscarriage, preterm birth, low birth weight, stillbirth, Down syndrome, schizophrenia, childhood cancer and autism-increases with maternal and paternal age (Jacobsson et al., 2004; Durkin et al., 2008; Johnson et al., 2009; Lopez-Castroman, et al. 2010; Yip et al., 2006). ${ }^{2}$

However, recent sociological and demographic evidence for a selection of low- and middle-income countries suggests that maternal age has a monotonic, non-linear positive relation with children's probability of secondary schooling completion and years of schooling, even after adjusting for socioeconomic resources (Fall et al., 2015). Similar results have been recently found for high-income countries as well (Myrskylä et al.,

${ }^{2}$ According to this branch of research, negative consequences of postponement also persist in the long run. Children of older parents, indeed, have greater risk of Alzheimer's disease (Rocca et al., 1991), cancer (Hemminki \& Kyyrönen, 1999), and, most importantly, old age mortality (Kemkes-Grottenthaler, 2004). 
2017). Mare and Tzeng (1989) showed that also delayed fathering is beneficial for sons' educational attainment, even once family background composition is taken into account. Positive effects of later parenthood on children's outcomes could derive from more 'readiness' and higher satisfaction from childbearing amongst older fathers and, especially, mothers, which could translate into better parenting practices (Fall et al., 2015). These positive effects may also be explained by a macro-level mechanism. Indeed, postponing parenthood means that a child is born at a later calendar year and a later cohort, when quality of life, health conditions and life expectancy-as well as educational levels-have increased (Myrskylä et al., 2013). In other words, delaying motherhood may positively affect children's educational outcomes solely because postponement means that the child is born in a later birth cohort (Barclay \& Myrskylä, 2016).

Most studies, especially in the medical literature (e.g. Johnson et al., 2009; LopezCastroman et al., 2010; Yip et al., 2006), considered maternal age and paternal age separately, often controlling for the age of the partner to study the independent effect of each parent's age. For instance, postponement of both motherhood and fatherhood appears to be protective for the risks of children's gastroschisis, but detrimental for the risks of omphalocele, spina bifida, all orofacial clefts, and septal heart defects (Fisk Green et al., 2010). Only few scholars investigated the combination between the two, finding mixed results according to the outcome, still limited to children's health-especially, congenital anomaliesand not extended to their education. However, despite mixed evidence on the combination between maternal and paternal age, it has been shown that the higher the age difference in the couple, the higher the negative consequences for the children (ibidem).

Although all age at parenthood effects may be influenced, at least partially, by selection on unobservable characteristics, the latter is especially likely in the case of parents' age difference at childbirth. Consistent with the sociological, demographic and anthropological research, the magnitude of the age difference between partners is an indicator of the egalitarian nature of the relationship between men and women (Atkinson \& Glass, 1985; Cain, 1993; van de Putte et al., 2009), and a large age difference may represent an important element impeding conjugal intimacy and a good relationship quality (Barbieri \& Hertrich, 2005), which may have negative effects for the children. However, deviations from perfect age homogamy are likely to have different implications for couples, and their children, depending on the sex of the older parent. In fact, in most countries, it has normative status for the male partner to be older than the female partner at marriage (Shehan et al., 1991; Ní Bhrolcháin, 2005), especially where traditional gender attitudes prevail (Jensen \& Thornton, 2003), like in Italy (Guetto et al., 2015). Moreover, even a relatively small age difference in favour of the woman may be associated with lower relationship quality between partners or reduced paternal involvement in childrearing. Empirical evidence suggests, for instance, that age differences between partners are related to higher risks of divorce only if the wife is older than the husband (Lehrer, 2008). Thus, only those couples in which the mother is older than the father should be negatively associated with children's educational outcomes.

\section{Heterogeneity in the effects of age at parenthood: social origins and birth order}

If late parenthood positively affects children's educational outcomes, then the increasing postponement of the transition to motherhood and fatherhood occurred in the last 
decades may contribute to increase IEO. Indeed, highly-educated men and women were the forerunners in delaying parenthood, and they are still those who postpone births once they have finished school and entered the labour market and the best career tracks (Bhrolcháin \& Beaujouan, 2012; Cantalini, 2020). Conversely, less advantaged individuals, especially women, are more likely to experience teenage and early births, which do not only negatively affect their educational and occupational success, but are also detrimental for their children's schooling.

However, whether the increasing delay in childbearing increases IEO also depends on whether postponement is more beneficial for low- or high-SES children. According to the DDT (McLanahan, 2004), family changes associated to the second demographic transition, including trends in fertility timing, would contribute to an increase in children's resources especially amongst children in the top socioeconomic strata. At the same time, disparities amongst children would increase as the penalty for early parenthood is higher for low-SES families.

In analytical terms, the study of whether (the changes in) family behaviours, e.g. the postponement of childbearing, favour or hinder the reproduction of IEO requires the analysis of its heterogeneous effects on children's educational outcomes, through the estimation of interactions between the demographic factor considered and parental SES. For instance, according to the DDT, the diffusion of divorce and single-parent households would increase inequalities as non-intact families would have a negative effect on children's outcomes, especially amongst less-educated and poorer families. However, whereas some studies did find that socioeconomically advantaged families manage to shelter their pupils from the consequences of parental break-up (Amato \& Anthony, 2014; Grätz, 2014), others found stronger penalties amongst highly-educated families (Bernardi \& Boertien, 2016, 2017; Bernardi \& Radl, 2014; Brand et al., 2019). More recently, Bernardi and Comolli (2019) and Guetto and Panichella (2019) suggested that heterogeneity in divorce penalty depends on the combination between social background and the educational outcome considered: the smallest penalty will be observed for very rare-e.g. tertiary education attainment for children of disadvantaged families-and very common outcomes-e.g. high-school completion for children of advantaged families.

Extending this line of reasoning to the parental age at birth, a smaller penalty of early parenthood (as well as a smaller premium of late parenthood) could be found amongst children of low-SES parents as far as enrolment in the academic track is concernedvery rare outcome for children of low-SES parents. At the same time, the early parenthood penalty (and the late parenthood premium) should be smaller amongst children of high-SES families when it comes to the probability of being enrolled in any 5-year upper-secondary school-very common outcome for children of high-SES parents.

There is at least another important factor of heterogeneity that is worth considering in the analysis of the relationship between parental age at birth and children's outcomes, namely the birth order. Indeed, the huge delay in fertility timing during the second demographic transition caused a decrease in fertility, especially in births at higher parities (De Sandre et al., 1997; Dalla Zuanna, 2004; Salvini, 2004). Moreover, children born to older parents are usually higher-order births and have, on average, more siblings than children born to younger parents. Since both large sibship size and high birth order negatively affect achievement (Blake, 1989; Paulhus et al., 1999; Ferrari \& Dalla Zuanna, 2010), 
children born later in parents' life course may have lower life chances than children born to parents at earlier ages (Mare \& Tzeng, 1989).

Given the strong interconnection between parental age at childbirth and birth order, stratifying the analysis of children's educational outcomes by parity seems to be particularly important. Only few studies, however, focused on the heterogeneous effects of age at parenthood according to birth order, exclusively in the medical literature, showing mixed results. Some studies showed that postponement appears to be detrimental for some health outcomes, such as the risk of autism spectrum disorder, especially for firstborn offspring (Durkin et al., 2008); others did not find relevant differences for other health outcomes, such as birth weight and height, as well as for years of schooling (Fall et al., 2015).

\section{Research hypotheses}

In light of the previous literature, we outline the following research hypotheses. First, we expect that the postponement of motherhood and fatherhood is beneficial for children's education, independently from the outcome studied (late parenthood premium hypothesis), whereas teenage or early parenthood is detrimental for offspring's educational success (early parenthood penalty hypothesis). Clearly, the two hypotheses are the same if parental age at birth is positively and monotonically related to children's educational attainment. However, early and late parenthood represents very different phenomena, and while both the medical and sociodemographic literature agree that teenage parenthood is likely to be detrimental for both mothers and children, expectations concerning later parenthood differ. This opens up the possibility for nonlinear effects, which will be taken into account in our empirical strategy.

Second, while we expect different associations depending on parental SES, theoretical expectations are not univocal; following the DDT, the penalty related to both early motherhood and fatherhood should be higher amongst children from a disadvantaged background, whereas the premium related to late parenthood should be stronger amongst children from highly-educated families (DDT hypothesis). The latter hypothesis can be seen as an instance of the compensatory advantage mechanism (Bernardi, 2014), according to which an unfavourable circumstance, like being born to relatively young parents, is less negatively consequential for the educational attainment of children of high-SES parents. Similarly, the effects of a more favourable event, i.e. being born to relatively old parents, should be more beneficial for children of high-SES families, pointing to a pattern of cumulative advantage.

However, following the recent literature on the divorce effects on children's outcomes, results may also depend on the combination between parental SES and the educational outcome considered (common/rare outcomes hypothesis). According to such hypothesis, age at parenthood effects (i.e. the early parenthood penalty and the late parenthood premium) should be smaller amongst children of high-educated families if upper-secondary school enrolment is considered (very common outcome), and amongst children of low-educated families if the enrolment in the academic track is considered (very rare outcome).

Third, as far as differences by birth order are concerned, we refrain from formulating precise expectations. There is only medical evidence in this respect, and the results are mixed. However, it is interesting to investigate whether our hypotheses are confirmed across all parities. 
Finally, we expect children's educational outcomes to be the highest in case of parental age homogamy, being it a proxy of equality and relationship quality in the couple, as well as in the couples where the father is slightly older than the mother. Conversely, educational outcomes should be worse when the mother is older than the father, because these couples could be selected not only in terms of lower relationship quality but also in terms of reduced paternal involvement in childrearing (age difference hypothesis).

\section{Data, variables and methods}

\section{Data and variables}

We used pooled quarterly data from the Italian labour force survey (ILFS), for the years from 2005 to 2014. The ILFS is a nationally representative survey of Italian households carried out by the Italian National Institute of Statistics (ISTAT) on all household members aged at least 15. This survey includes detailed information on the household structure and the characteristics of their members (e.g. sex, age, education and occupation). We focus only on children living with both biological parents, since we aim at estimating the effects of both age at motherhood and fatherhood on children's educational attainment, controlling for detailed information on both parents' education and social class. We also replicate the analysis considering single mothers and fathers, and results (available on request) are consistent with those presented in the "Empirical evidence" section. After listwise deletion of missing cases, the final analytical sample includes 213,538 individuals aged 15 to $18 .^{3}$

The dependent variables are two measures of educational attainment: (a) the probability of being enrolled in a 5-year upper-secondary school; (b) the probability of being enrolled in the two most prestigious curricula of the academic track (liceo classico and liceo scientifico). By looking at both the vertical and the horizontal dimensions of IEO, it is possible to consider two very different educational outcomes, with the aim of highlighting possible heterogeneity in the effects of parental age amongst social groups (Guetto \& Panichella, 2019). The first variable considers the vertical dimension, analysing the probability of not being in a vulnerable condition for children: the nonenrolment in the educational system during the years of compulsory schooling (6-16 years of age), or the attendance of a 2/3-year vocational course which does not give access to university. This condition is actually not uncommon in the Italian context: in our analytical sample, the share of children not enrolled in a 5-year upper-secondary track has only slightly decreased in the period studied, shifting from 14 to $12 \%$. The second variable considers the horizontal dimension of education analysing the probability of being enrolled in the most prestigious and demanding track, which is commonly seen as the 'main route' to enter university.

The independent variables are age at motherhood and age at fatherhood, which have been operationalised with a set of dummy variables from up to 20 years to $40+$ years (45+ for fathers, since men are more likely than women to become parents after age 40). The inclusion of yearly dummies for age at parenthood in the models, instead of 5year age intervals or polynomial transformations, has been made possible by the large sample size and allows to best capture possible nonlinear effects.

${ }^{3}$ We also included children aged $17-18$ in order to account for students' possibility to change uppersecondary track at older ages. Results (available on request) do not change if we focus on a more restrictive sample of individuals aged 15-16. 
The main control variables regard the social background of origin, which has been measured with two indicators. The first is the social class of origin, measured through a variable which considers all possible combinations of both parents' social class at the time of the interview. Social class is operationalised with a reduced version of the Erikson-GoldthorpePortocarero class scheme (EGP, Erikson et al., 1979) including five categories: (a) bourgeoisie (I-II); (b) white collars (IIIa); (c) petite bourgeoisie (IVabc); (d) working class (IIIb, V, VI, VIIa, VIIb) and (e) unemployed or inactive. The second variable considers all possible combinations of the educational level of both parents, operationalised with the highest level of detail available in the data: (a) elementary or no title, (b) lower-secondary, (c) vocational upper-secondary (2-3 years), (d) upper-secondary (5 years) and (e) tertiary. Some models, for the sake of parsimony, include a three-category variable, based on the highest educational level between parents: up to vocational upper-secondary (2-3 years), upper-secondary (5 years) and tertiary (see the "Methods and empirical strategy" section).

Models also control for dummies for region of residence, dummies for each trimester of interview (from the first trimester of 2005 to the fourth trimester of 2014), birth order (only child, first-born, second-born, third-born or more), family size (less than three children; three children or more), place of birth (Italy or abroad), age and sex.

\section{Methods and empirical strategy}

Empirical analyses are based on a set of linear probability models (LPMs) estimated applying the weights provided by the ILFS and with robust standard errors. We opted for LPMs rather than logit or probit models, specifically addressed to analyse binary dependent variables, because of the more direct interpretation of the coefficients as well as their safer comparability across models (Mood, 2010).

The analytical strategy is divided into two steps. The first step aims at studying the overall association between age at motherhood (and fatherhood) and children's educational outcomes. Four models are estimated, separately for the effect of mother's and father's age at birth:

$$
\begin{aligned}
& \text { M1 }: Y=\beta_{1}+\beta_{2} \text { AgeM }+\varepsilon \\
& \text { M2 }: Y=\beta_{1}+\beta_{2} \text { AgeM }+\beta_{3} \text { AgeF }+\varepsilon \\
& \text { M3 : Y }=\beta_{1}+\beta_{2} \text { AgeM }+\beta_{3} \text { AgeF }+\beta_{4} C L+\beta_{5} E D U+\varepsilon \\
& \text { M4 : Y }=\beta_{1}+\beta_{2} \text { AgeM }+\beta_{3} \text { AgeF }+\beta_{4} C L+\beta_{5} E D U+\beta_{6} Z+\varepsilon
\end{aligned}
$$

Model 1 estimates the gross effect of age at motherhood (AgeM) —and, separately, age at fatherhood $(\mathrm{AgeF})$ - on the two educational outcomes considered, whereas Model 2 includes the age of both parents at birth. Model 3 controls for the social background of origin, with the inclusion of two-way interactions between both parents' social class $(C L)$, on the one side, and both parents' educational level $(E D U)$, on the other side. Model 4 adds a vector $(Z)$ for the additional sociodemographic controls described above.

The second step of the empirical strategy focuses on the heterogeneity in the association between age at parenthood and children's outcomes. First, in order to study how the effects of parental age vary according to social origins, a further model is estimated with the same specification of Model 4, but with an interaction between parental education (three-category version) and age at childbirth $(A g e M \times E D U ; A g e F \times E D U)$. For the sake of parsimony, only 
the interaction between parental education and age at parenthood is considered, because parental education represents a variable more strongly associated to children's educational choices compared to parental social class (Ballarino \& Schadee, 2010). Second, Model 4 is augmented with an interaction between parental age and a less detailed version of birth order (only child, first-born, second-born or more), aiming at studying the heterogeneity of the association according to birth order. Finally, a model is estimated using the difference between mother's and father's age at birth as the independent variable, net of the maternal age at childbirth, to investigate if the magnitude of age difference between parents is associated to children's educational outcomes.

\section{Empirical evidence}

\section{Age at parenthood and children's educational outcomes}

Figures 1 and 2 show the results regarding the overall association between parental age and (a) the probability of being enrolled in a 5-year upper-secondary school and (b) the probability of being enrolled in the academic track, respectively. The first panel of the graphs confirms that postponement of parenthood has a strong, bivariate positive effect on both children's educational outcomes (model 1). If the negative consequences related to teen and early childbearing are evident for both the probabilities of general enrolment and enrolment in the most prestigious track, the late parenthood effects appear to be stronger if the latter is considered. For instance, the predicted probabilities of enrolment for children who have mothers aged 30 at birth are 24.1 percentage points (p.p.) higher

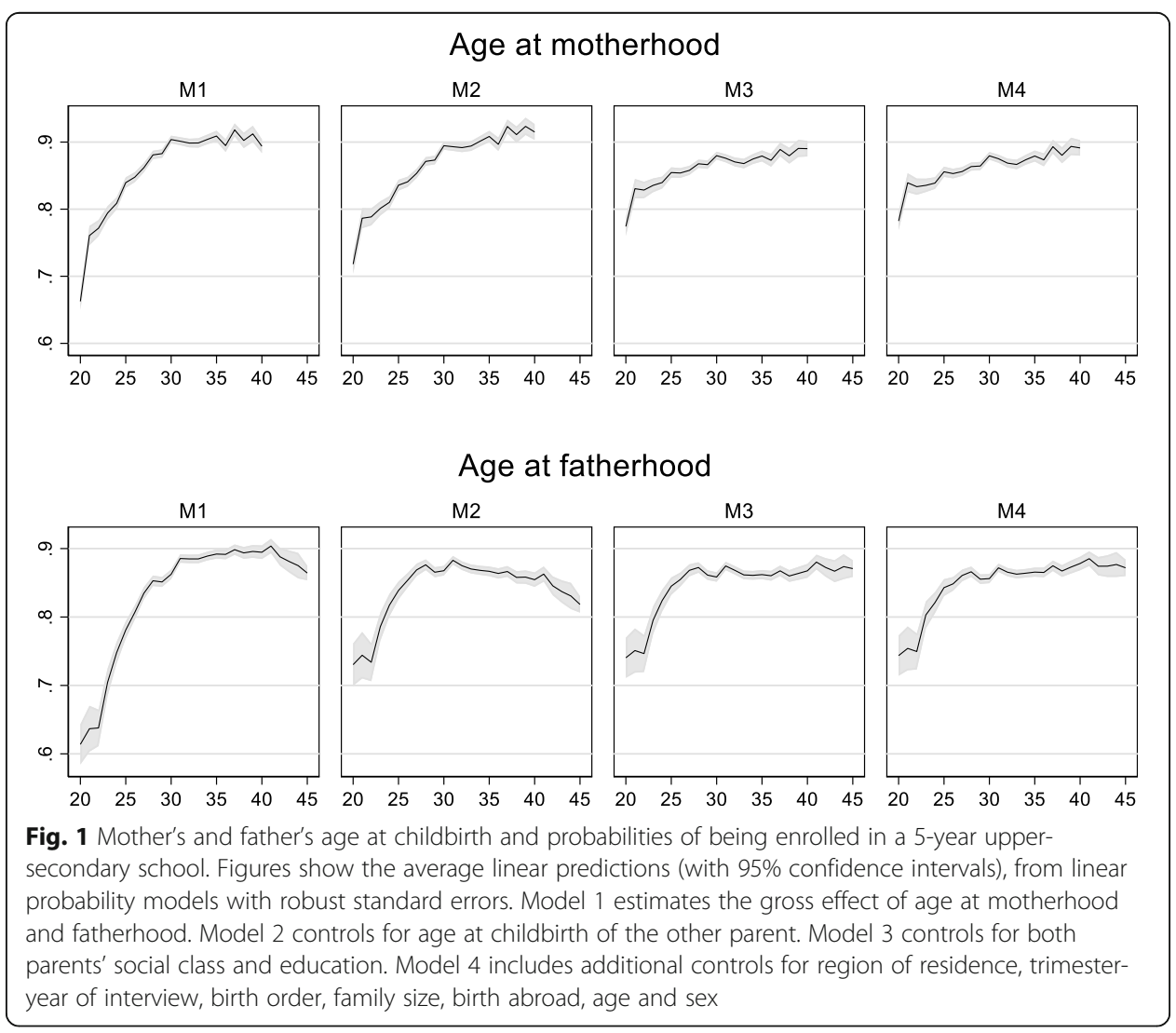




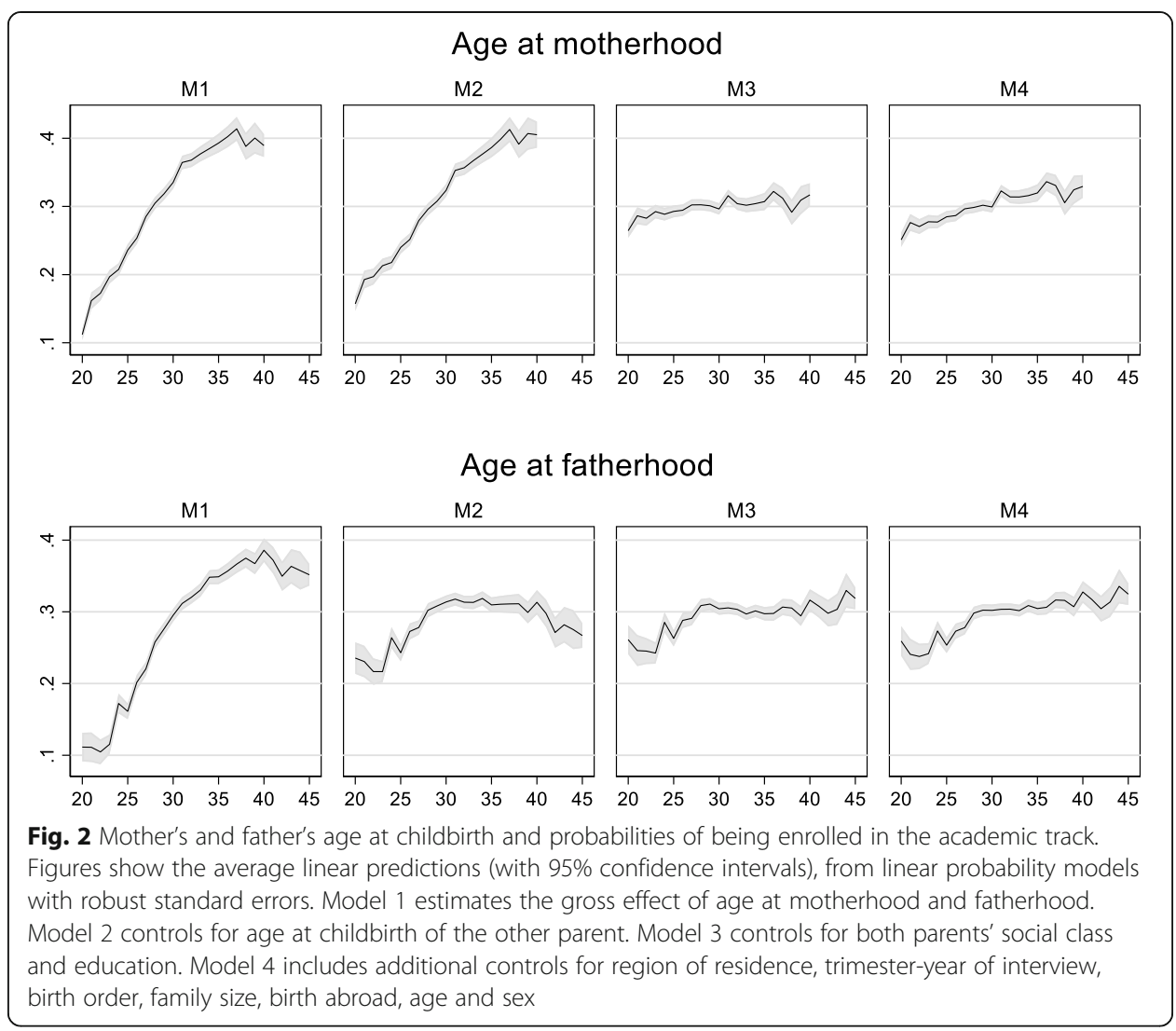

than those with mothers aged less than 20 at birth $\left(\overline{p r}_{30}-\overline{p r}_{<20}=90.4-66.3=24.1\right)$, and only 1.0 p.p. higher than those with mothers aged more than 40 at birth $\left(\overline{p r}_{30}-\overline{p r}_{>40}=\right.$ $90.4-89.4=1.0$; Fig. 1). The figures are 22.3 p.p. and -5.4 p.p. as for the probabilities of entering the academic track, respectively (Fig. 2). Results suggest that children maximize their chances to enrol in a 5-year upper-secondary school if the mother was aged 30 or more at childbirth, whereas they experience the highest probabilities of enrolment in the academic track if the mother was aged more than 35 at birth. Figures are not different for what paternal age at childbirth is concerned, despite a slightly stronger effect of postponement, presumably related to the oldest age at parenthood for men.

The second panel of the graphs shows that part of the association between parental age at birth and children's outcomes is accounted for by the age at childbirth of the other parent (model 2). This is especially true if we look at the positive effect of age at fatherhood on the probability of being enrolled in the academic track, which decreases substantially when the mother's age at childbirth is controlled for. In this case, predicted probabilities increase from 11.1 to $23.6 \%$ if father's age at birth is lower than 20, remain stable at father's age 30 (from 29.5 to $31.4 \%$ ), and decrease from 38.6 to $31.1 \%$ at father's age 40 (Fig. 2).

A substantial share of the advantages of later parenthood-as well as of the disadvantages of teenage and early parenthood-can be further accounted for by the higher educational and class attainment associated with it (model 3, third panel). Indeed, controlling for both parents' education and social class substantially reduces the higher enrolment probabilities found for children born to older parents and increases those 
found for children born to young parents, especially as far as mothers and the enrolment in the academic track are concerned. The differences in the predicted probabilities between children born to mothers aged 30 at birth and children of teenage mothers reduce to 10.6 p.p. $\left(\overline{p r}_{30}-\overline{p r}_{<20}=88.0-77.4=10.6\right)$ for the probability of enrolment and even to 3.2 p.p. $\left(\overline{p r}_{30}-\overline{p r}_{<20}=29.6-26.4=3.2\right)$ for the probability of entering the academic track. If we compare children from mothers aged 30 at birth with children from mothers aged 40 or more, probabilities of general enrolment and enrolment in the academic track become 1.0 p.p. $\left(\overline{p r}_{30}-\overline{p r}_{>40}=88.0-89.0=-1.0\right)$ and 2.1 p.p. $\left(\overline{p r}_{30}-\overline{p r}_{>40}=29.6-31.7=-2.1\right)$ lower for the former, respectively.

Although important to obtain a more conservative 'net' effect of the age at parenthood, it should be said that by including controls for education and social class we are, at least in part, capturing the postponement effect itself, to the extent that childbearing delay fosters educational and occupational attainment.

However, consistent with our early parenthood penalty and late parenthood premium hypotheses, even after controlling for additional sociodemographic characteristics, including family size and parity, being born to a teenage mother or (especially) father remains associated with lower enrolment probabilities compared to children of parents aged around 30 at childbirth, whereas postponing parenthood after age 40 or 45 positively affects children's educational outcomes (model 4 , fourth panel). ${ }^{4}$ Hence, even with full controls, the association remains statistically significant and substantially not trivial. This positive association is almost linear if age at motherhood is considered, whereas it is more heterogeneous as for age at fatherhood: the probabilities of general enrolment, which are very low in the case of teenage fathers, increase with paternal age at birth up to age 30 and then remain stable, while the probabilities of entering the academic track are almost flat until age 25, then increase up to age 30, remain stable thereafter and finally increase again for children with fathers aged more than 40 at birth.

It is worth noting that compositional effects due to the age at childbirth of the other parent (model 2), social background (model 3) and additional controls (model 4) change according to the parent and the educational outcome studied. For instance, the mother's age at childbirth is crucial to explain the association between age at fatherhood and the probability of entering the academic track, whereas social origins matter more for the association between age at motherhood and children's outcomes, especially if the probability of enrolling in the academic track is considered.

\section{Heterogeneity by parental education and birth order}

We turn now to the second step of the empirical strategy, aiming at studying the heterogeneity of the association between age at parenthood and children's educational outcomes. Figures 3 and 4 present results focusing on differences by social origins, measured by the highest of parents' educational attainment. When it comes to enrolments in 5-year upper-secondary schools, our association of interest exists only amongst children of low-educated parents, whereas the line is almost flat amongst children of the middle- and, especially, tertiary-educated. Indeed, early parenthood is

${ }^{4}$ Coefficients associated to all control variables included in Model 4 of Figs. 1 and 2 can be found in Table 1 in the 'Appendix' section. Net of parental SES and migration background, later-born children living in large families are found to have worse educational outcomes. 


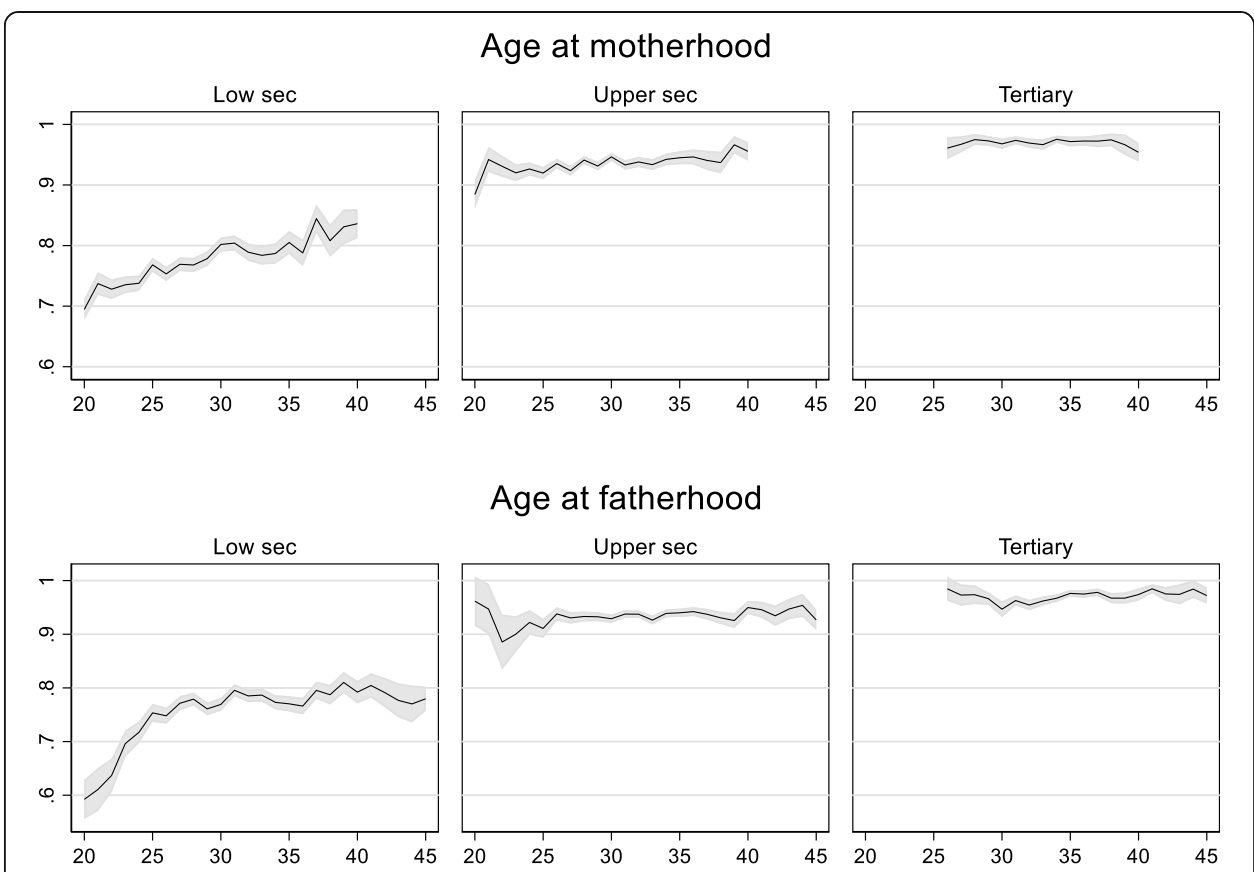

Fig. 3 Mother's and father's age at childbirth and probabilities of being enrolled in a 5-year uppersecondary school, by parental education. Figures show the average linear predictions (with 95\% confidence intervals), from linear probability models with robust standard errors. Models control for both parents' social class, region of residence, trimester-year of interview, birth order, family size, birth abroad, age and sex

associated with lower probabilities of enrolment only amongst those with low-educated parents. Even the positive effects of postponing childbearing at later ages appear only for children of low-educated parents (Fig. 3). ${ }^{5}$

One can also observe that curves for children of low-educated parents resemble those presented for the whole sample (see Fig. 1, model 4): predicted probabilities increase almost linearly if age at motherhood is studied, whereas they dramatically increase from age 20 to 30 and remain stable thereafter if age at fatherhood is considered. For instance, if we compare children of low-educated parents aged 25 at childbirth and children of low-educated parents aged 40 at childbirth, the difference in the predicted probability of being enrolled in any 5 -year upper-secondary school is 6.8 p.p. ( $\overline{p r}_{>40^{-}}$ $\left.\overline{p r}_{25}=83.6-76.8=6.8\right)$ as for maternal age and 3.8 p.p. $\left(\overline{p r}_{>40}-\overline{p r}_{25}=79.2-75.4=\right.$ 3.8) as for paternal age. ${ }^{6}$ If we make the same comparison amongst the children of the tertiary educated, the figures are -0.8 p.p. $\left(\overline{p r}_{>40}-\overline{p r}_{25}=95.4-96.2=-0.8\right)$ and 0.8 p.p. $\left(\overline{p r}_{>40}-\overline{p r}_{25}=97.4-96.6=0.8\right)$, respectively.

Concerning enrolments in the academic track, differences are less evident, but still point to a stronger disadvantage related to early childbearing and a stronger advantage related to later parenthood for children of low- and middle-educated parents (Fig. 4). If amongst children of tertiary-educated parents, the age gradient is almost flat (for age at fatherhood) or it does not show a clear trend (for age at motherhood), it is positive for

\footnotetext{
${ }^{5}$ Curves for children of the tertiary educated start at age 25 since it is unlikely to attain tertiary education earlier, especially for the cohorts of parents observed in our sample. Indeed, the Italian university system was characterised by 4-6 years degree programs until 2002.

${ }^{6}$ Differences are even stronger if very late births (at age 40 or more) are compared to very early births (at age 20 or less), which are not uncommon for the low-educated, pointing to 14.1 p.p. for maternal age at childbirth and 20.0 p.p. for paternal age at childbirth.
} 


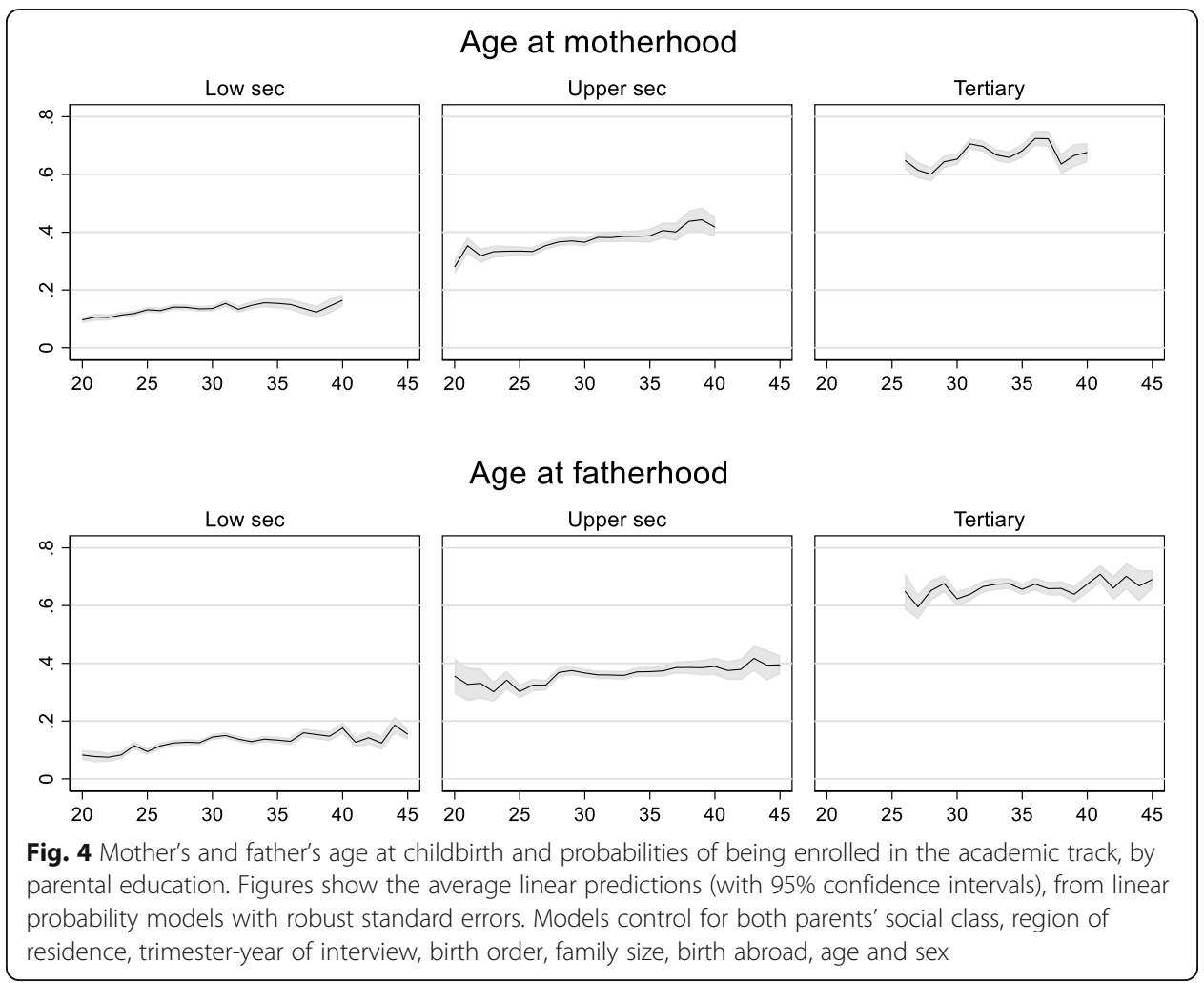

children of the low-educated ones, pointing to average differences of around 3.3-8.1 p.p. when births at age 25 and births after age 40 are compared. It should be noted that, differently from general enrolments, differences are even stronger amongst children of upper-secondary educated parents.

Our results are only partially in line with the DDT hypothesis. If it is true that the negative effects of early childbearing are stronger amongst children of low-educated families, it is also true that they benefit more from the parenthood postponement at later ages, albeit they are not able to reach the levels of the predicted probability of families with higher education. To some extent, moreover, results are partially consistent to our common/rare outcomes hypothesis as well, for which the pattern of heterogeneous effects should change based on the combination between parental SES and the educational outcome considered. In fact, children of tertiary-educated parents are always less, if at all, influenced by age at parenthood. Conversely, children of low-educated families benefit the most from late parenthood if the general enrolment is considered, whereas fertility delay is more beneficial for the children of middle-educated families if the enrolment in academic track is studied. We will come back on this in the concluding section of the paper.

Figures 5 and 6 show how the association between age at parenthood and children's educational outcomes changes according to birth order. Results show that only children are less strongly affected by parental age at childbirth. This may be explained by the fact that parents can transmit all their (cultural and economic) resources to them, independently from the timing of fertility.

The comparison between first- and second-born (or more) concerning the probability of enrolment in any upper-secondary school suggests a more negative effect of early childbearing amongst the latter, who are significantly penalised if their mothers and, 


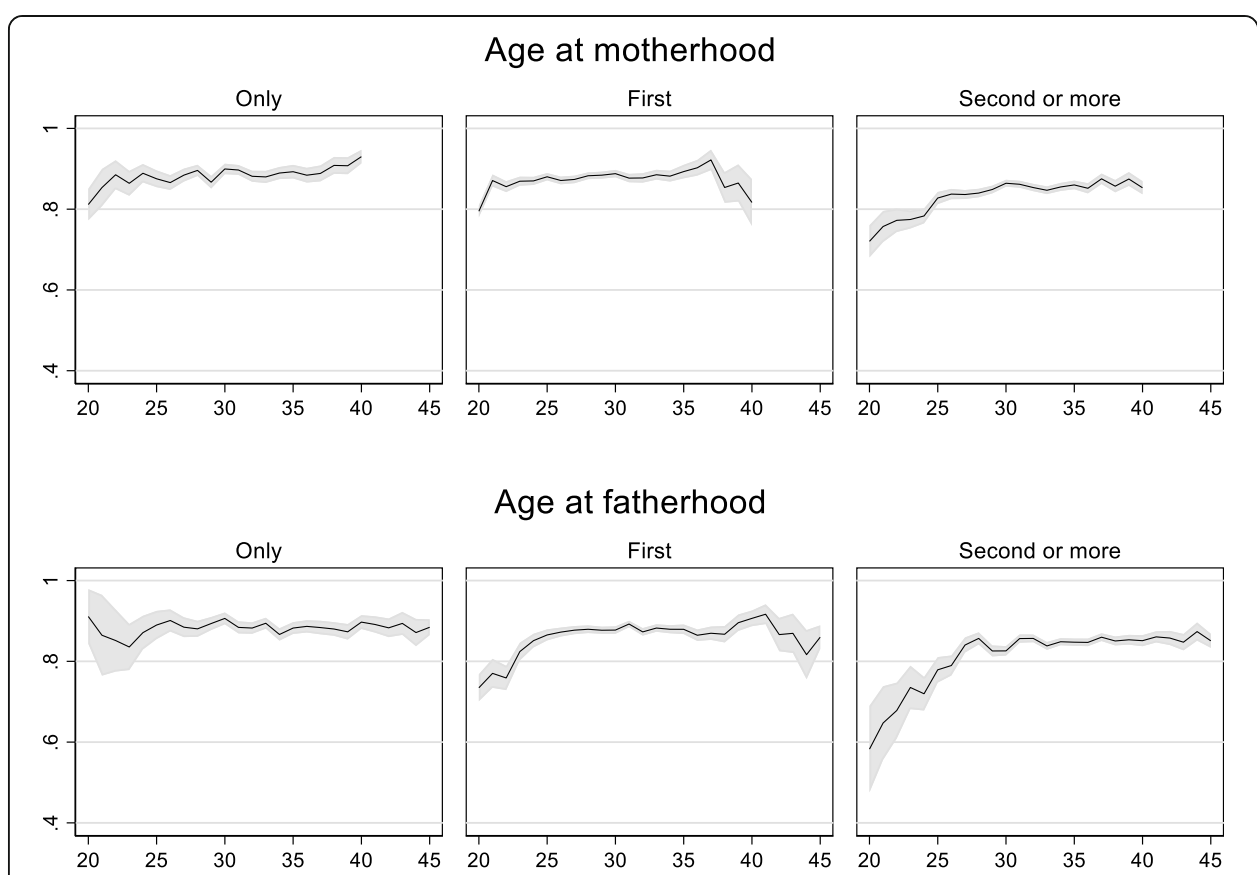

Fig. 5 Mother's and father's age at childbirth and probabilities of being enrolled in a 5-year uppersecondary school, by birth order. Figures show the average linear predictions (with 95\% confidence intervals), from linear probability models with robust standard errors. Models control for both parents' social class and education, region of residence, trimester-year of interview, birth abroad, age and sex

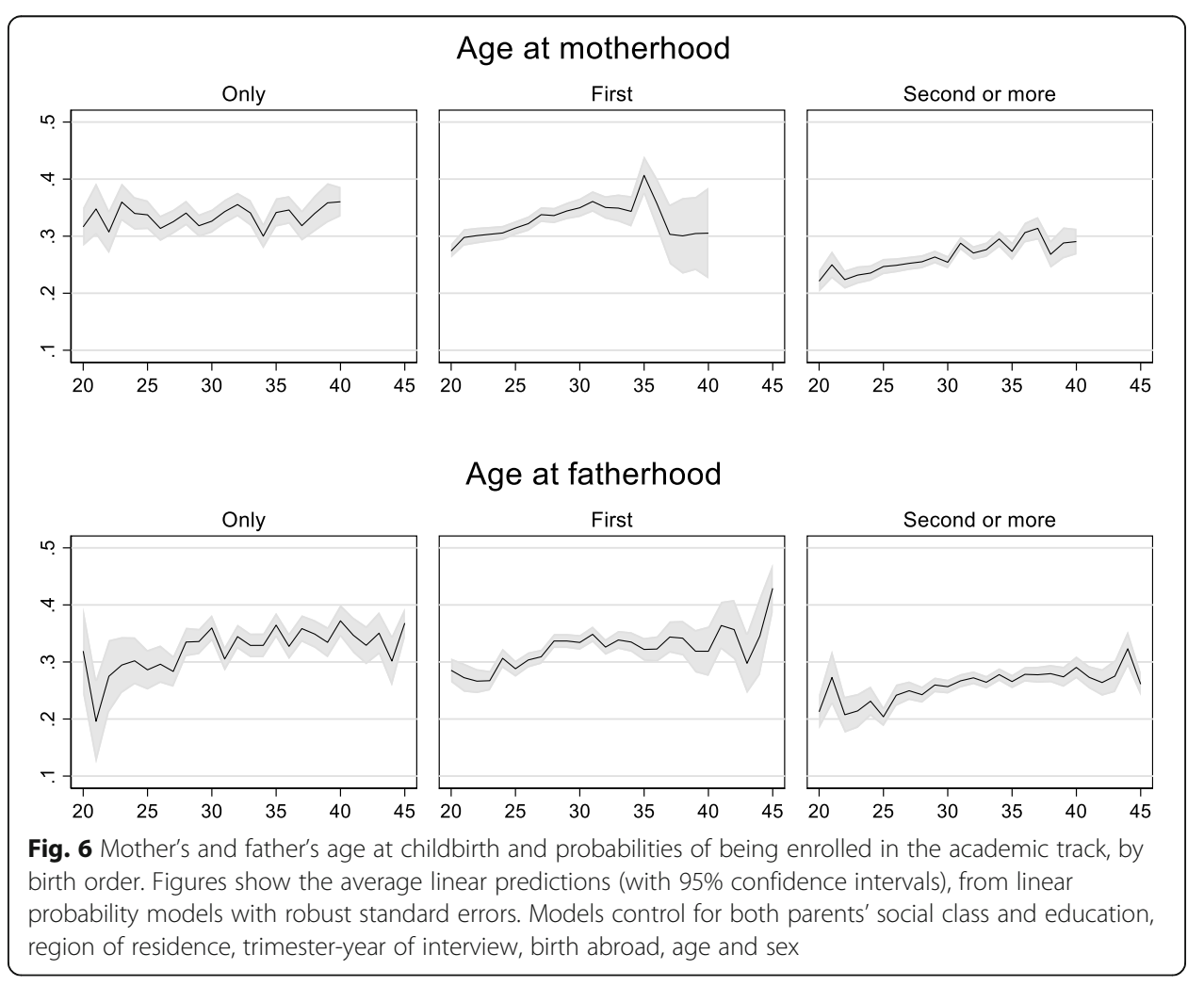


especially, fathers were teenagers at childbirth. For instance, later-born children with fathers aged 20 or less at childbirth have 24.3 p.p. lower $\left(\overline{p r}_{<20}-\overline{p r}_{30}=58.3-82.6=\right.$ -24.3) probability of enrolment with respect to later-born with fathers aged 30 at birth. The same difference is 13.9 p.p. $\left(\overline{p r}_{<20}-\overline{p r}_{30}=73.5-87.4=-13.9\right)$ if first-born children are considered. Postponement of parenthood at older ages does not affect this educational outcome; indeed, curves related to parental age at birth become flat after age 30 .

If we consider the probability of choosing the most prestigious track, the beneficial effects of postponement appear more clearly, primarily amongst second-born. However, later fatherhood seems to be important for the first-born children as well, who have the highest probabilities of entering the academic track if their fathers postpone first parenthood after age 45 .

Finally, Fig. 7 presents the predicted probabilities of being enrolled in a 5-year upper-secondary school (left panel) and in the academic track (right panel), by parental age difference (father-mother). Children's educational outcomes are worse in families where the mother is older than the father. Predicted probabilities increase almost linearly up to an age difference of 2-4 years in favour of the father, and then increase at a slower rate-as for the enrolment in the academic track-or remain stable-as for the general enrolment. These findings are consistent with our age difference hypothesis, according to which children maximize their educational opportunities either when the parents have approximately the same age or when the father is slightly older than the mother.

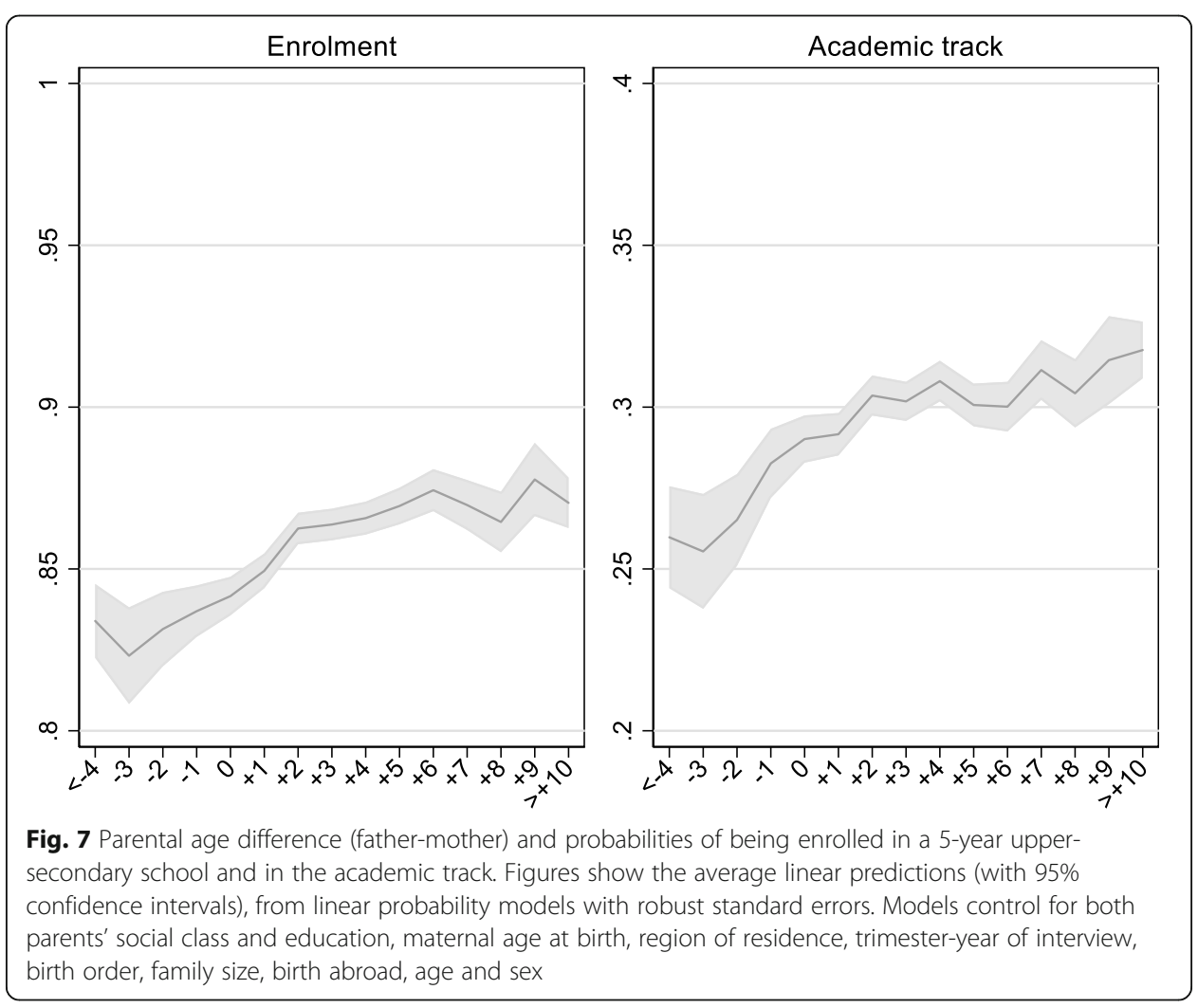




\section{Conclusion}

This paper analysed the association between age at parenthood and children's educational outcomes at the upper-secondary level in Italy, a latecomer of the second demographic transition. To the best of our knowledge, this issue has not been studied yet in the Italian context, although it allows to directly compare the demographic and sociological research with the medical literature, which highlighted several negative consequences related to late parenthood. This work also focused on the heterogeneity of this association, analysing how it varies amongst different social groups, and considering both the vertical and the horizontal dimensions of inequality, i.e. the probability of being enrolled in a 5-year upper-secondary school and the (unconditional) probability of entering in the academic track, which is the most important and prestigious school in the Italian educational system. The analysis of these two opposite educational outcomes allowed highlighting how the effect of late parenthood-as well as those of other nonstandard family arrangements-changes on the basis of the outcome considered (Guetto \& Panichella, 2019).

In general, ceteris paribus, late parenthood is positively associated with educational attainment, whereas early parenthood negatively affects children's educational outcomes-i.e., both the late parenthood premium and the early parenthood penalty hypotheses are supported. These results resemble very closely those obtained in recent socio-demographic studies concerning other countries (Fall et al., 2015; Fishman \& Min, 2018; Myrskylä et al., 2017) and confirm that postponing parenthood at older ages, despite potentially having negative effects on children's health, is at least beneficial for their educational success.

There are, however, interesting differences when different educational outcomes are considered. The negative consequences of early childbearing are evident for both the probabilities of general enrolment and enrolment in the most prestigious academic track, but the late parenthood effects only appear to be strong if the latter is considered. Moreover, a substantial part of the disadvantage of the children of young mothers on general enrolment is explained by their low socioeconomic background, although it remains substantially and statistically significant. This compositional effect is even more important when the 'opposite' educational outcome is considered, especially as far as the effect of age at motherhood is concerned.

Therefore, a substantial part of the negative effect of early parenthood is mediated by the fact that having a child at an early age has important negative effects on the educational and occupational career, especially amongst women (Cantalini, 2020). This negative effect, however, creates a process of accumulation of disadvantages that persists in the long-run, also involving the educational achievement of their children. This process explains the total amount of the negative effect on the chances of entering the academic track, whereas in the case of the non-enrolment, there are other mechanisms of disadvantage related to early motherhood that are not captured by the control for social origin included in the model.

But how does late parenthood influence the inequalities of educational opportunities? This work addressed this issue analysing how the association between age at parenthood and children's educational success varies amongst social groups with different resources and constraints. Indeed, not only are the highly-educated more likely to postpone parenthood and low-educated more likely to experience teenage 
and early births, but the effects of these behaviours change according to educational (and class) attainment. Our results showed that age at parenthood affects the educational achievement mostly for children of low- and middle-educated parents, although in the case of the enrolment in the academic track such effect is less evident. Hence, when parents from this group were younger at childbirth, they increase their distance from highly-educated parents; on the contrary, when they postpone parenthood to later ages, they are able to reduce educational inequality, although they do not catch up the levels of the most advantaged social groups. While in the latter case there is a process of (partial) reduction of IEO, in the former case, there is a process of intergenerational accumulation of disadvantages: not only those with poor educational and employment careers have a greater chance of having children at relatively young age, but their descendants are also those that experience the strongest negative effects of early parenthood on their educational achievement.

In light of these results, we argue that the DDT only partially applies to the Italian case. Indeed, if the DDT helps to account for the more negative effects of early childbearing for low-SES children (the DDT hypothesis is partially supported), focusing on the heterogeneity between social origins and educational outcome allows to further understand that fertility postponement is more beneficial for their enrolment probabilities because the children of the tertiary educated are always 'protected' by their highSES families, independently from age at parenthood (the common/rare outcomes hypothesis is partially supported).

Results also showed that the association between age at parenthood and children's educational achievement changes according to another source of heterogeneity: the birth order. Similar to the resource dilution argument (Blake, 1989), claiming that a high number of children in the household reduces their educational chances, our results showed that only children are less affected by age at childbirth, independently from the educational outcome considered, whereas there is a substantial effect amongst the first- and second-born (or more). The latter are particularly disadvantaged if the general enrolment is considered, and when the father was below 25 years of age at childbirth. Again, results change on the basis of the educational outcome considered: the beneficial effects of later parenthood appear more clearly amongst first- and, especially, later-born children when the chances of entering in the academic track are studied, whereas the negative effects of early parenthood are stronger amongst later-born as far as general enrolment is concerned.

Finally, also the parental age difference matters: children's educational opportunities are worse when the mother is older than the father, independently from the educational outcome considered. On the contrary, a family maximizes the educational outcomes of their children when the parents have similar age, or when the father is slightly older than the mother (age difference hypothesis supported). Although the issue deserves further attention, this result is likely affected by the selectivity of families composed by older mothers, which deviate from the predominant social norms, especially in the Italian context, and where fathers may be less involved in childrearing. Therefore, families, net of parental SES, maximize their children's educational success when their reproductive behaviour is closer to social norms. 


\section{Appendix}

Table 1 Beta coefficients (with 95\% c.i.) of control variables from Figs. 1 and 2 (model 4)

\begin{tabular}{|c|c|c|}
\hline & $\begin{array}{l}\text { Enrolment } \\
\text { (M4) }\end{array}$ & $\begin{array}{l}\text { Academic } \\
\text { (M4) }\end{array}$ \\
\hline \multicolumn{3}{|c|}{ Education of the parents (ref. Both lowsec) } \\
\hline \multirow[t]{2}{*}{ F lowsec-M uppersec } & $0.10^{* * *}$ & $0.12^{* * *}$ \\
\hline & $(0.10-0.11)$ & $(0.11-0.13)$ \\
\hline \multirow[t]{2}{*}{ F lowsec-M tertiary } & $0.11^{* * *}$ & $0.20^{* * *}$ \\
\hline & $(0.10-0.12)$ & $(0.18-0.22)$ \\
\hline \multirow[t]{2}{*}{ F uppersec-M lowsec } & $0.11^{* * *}$ & $0.11^{* * *}$ \\
\hline & $(0.10-0.11)$ & $(0.10-0.12)$ \\
\hline \multirow[t]{2}{*}{ Both uppersec } & $0.12^{* * *}$ & $0.25^{* * *}$ \\
\hline & $(0.11-0.12)$ & $(0.24-0.26)$ \\
\hline \multirow[t]{2}{*}{$\mathrm{F}$ uppersec- $\mathrm{M}$ tertiary } & $0.12^{* * *}$ & $0.37^{* * *}$ \\
\hline & $(0.11-0.13)$ & $(0.36-0.39)$ \\
\hline \multirow[t]{2}{*}{$\mathrm{F}$ tertiary-M lowsec } & $0.09^{* * *}$ & $0.24^{* * *}$ \\
\hline & $(0.08-0.11)$ & $(0.21-0.26)$ \\
\hline \multirow[t]{2}{*}{ F tertiary-M uppersec } & $0.12^{* * *}$ & $0.39^{* * *}$ \\
\hline & $(0.12-0.13)$ & $(0.37-0.40)$ \\
\hline \multirow[t]{2}{*}{ Both tertiary } & $0.12^{* * *}$ & $0.47^{* * *}$ \\
\hline & $(0.11-0.13)$ & $(0.46-0.49)$ \\
\hline \multicolumn{3}{|c|}{ Social class of the parents (ref. Both Bor) } \\
\hline \multirow[t]{2}{*}{ F Bor-M WhC } & $0.01^{*}$ & $-0.05^{* * *}$ \\
\hline & $(-0.00-0.01)$ & $(-0.06--0.03)$ \\
\hline \multirow[t]{2}{*}{ F Bor-M PB } & $0.02^{* *}$ & $-0.06^{* * *}$ \\
\hline & $(0.00-0.03)$ & $(-0.09--0.03)$ \\
\hline \multirow[t]{2}{*}{ F Bor-M WC } & $0.03^{* * *}$ & $-0.10^{* * *}$ \\
\hline & $(0.02-0.04)$ & $(-0.13--0.07)$ \\
\hline \multirow[t]{2}{*}{ F Bor-M Unempl } & 0.00 & $-0.14^{* * *}$ \\
\hline & $(-0.02-0.03)$ & $(-0.19--0.09)$ \\
\hline \multirow[t]{2}{*}{ F Bor-M Inact } & $0.01^{* * *}$ & $-0.09 * * *$ \\
\hline & $(0.01-0.02)$ & $(-0.10--0.07)$ \\
\hline \multirow[t]{2}{*}{ F WhC-M Bor } & 0.00 & $-0.04^{* * *}$ \\
\hline & $(-0.00-0.01)$ & $(-0.06--0.01)$ \\
\hline \multirow[t]{2}{*}{ Both WhC } & $0.01^{*}$ & $-0.10^{* * *}$ \\
\hline & $(-0.00-0.01)$ & $(-0.11--0.08)$ \\
\hline \multirow[t]{2}{*}{$\mathrm{F}$ WhC-M PB } & $0.01^{*}$ & $-0.08^{* * *}$ \\
\hline & $(-0.00-0.03)$ & $(-0.12--0.05)$ \\
\hline \multirow[t]{2}{*}{ F WhC-M WC } & 0.01 & $-0.17^{* * *}$ \\
\hline & $(-0.01-0.02)$ & $(-0.19--0.15)$ \\
\hline \multirow[t]{2}{*}{ F WhC-M Unempl } & 0.01 & $-0.16^{* * *}$ \\
\hline & $(-0.00-0.03)$ & $(-0.19--0.12)$ \\
\hline \multirow[t]{2}{*}{$\mathrm{F}$ WhC-M Inact } & $0.01^{* *}$ & $-0.16^{* * *}$ \\
\hline & $(0.00-0.02)$ & $(-0.17--0.14)$ \\
\hline \multirow[t]{2}{*}{$\mathrm{FPB}-\mathrm{M}$ Bor } & $-0.02^{* *}$ & $-0.08^{* * *}$ \\
\hline & $(-0.04--0.00)$ & $(-0.11--0.04)$ \\
\hline
\end{tabular}


Table 1 Beta coefficients (with 95\% c.i.) of control variables from Figs. 1 and 2 (model 4) (Continued)

\begin{tabular}{|c|c|c|}
\hline & $\begin{array}{l}\text { Enrolment } \\
\text { (M4) }\end{array}$ & $\begin{array}{l}\text { Academic } \\
\text { (M4) }\end{array}$ \\
\hline \multirow[t]{2}{*}{$\mathrm{FPB}-\mathrm{M}$ WhC } & 0.00 & $-0.12^{* * *}$ \\
\hline & $(-0.01-0.01)$ & $(-0.14--0.10)$ \\
\hline \multirow[t]{2}{*}{ Both PB } & $-0.01^{* * *}$ & $-0.13^{* * *}$ \\
\hline & $(-0.03--0.00)$ & $(-0.15--0.12)$ \\
\hline \multirow[t]{2}{*}{$\mathrm{FPB}-\mathrm{M} W \mathrm{~W}$} & $-0.03^{* * *}$ & $-0.19^{* * *}$ \\
\hline & $(-0.04--0.01)$ & $(-0.21--0.17)$ \\
\hline \multirow[t]{2}{*}{ F PB—M Unempl } & $-0.05^{* * *}$ & $-0.21 * * *$ \\
\hline & $(-0.08--0.02)$ & $(-0.24--0.18)$ \\
\hline \multirow[t]{2}{*}{ F PB-M Inact } & $-0.03^{* * *}$ & $-0.18^{* * *}$ \\
\hline & $(-0.04--0.02)$ & $(-0.20--0.17)$ \\
\hline \multirow[t]{2}{*}{ F WC-M Bor } & 0.01 & $-0.09^{* * *}$ \\
\hline & $(-0.01-0.03)$ & $(-0.13--0.05)$ \\
\hline \multirow[t]{2}{*}{$\mathrm{FWC}-\mathrm{M} W h \mathrm{C}$} & $0.01^{*}$ & $-0.16^{* * *}$ \\
\hline & $(-0.00-0.02)$ & $(-0.18--0.14)$ \\
\hline \multirow[t]{2}{*}{ F WC-M PB } & -0.01 & $-0.19^{* * *}$ \\
\hline & $(-0.03-0.01)$ & $(-0.22--0.17)$ \\
\hline \multirow[t]{2}{*}{ Both WC } & $-0.03^{* * *}$ & $-0.21^{* * *}$ \\
\hline & $(-0.04--0.02)$ & $(-0.22--0.19)$ \\
\hline \multirow[t]{2}{*}{ F WC-M Unempl } & $-0.08^{* * *}$ & $-0.24^{* * *}$ \\
\hline & $\left(-0.10 \_-0.07\right)$ & $(-0.26--0.22)$ \\
\hline \multirow[t]{2}{*}{ F WC-M Inact } & $-0.07^{* * *}$ & $-0.23^{* * *}$ \\
\hline & $(-0.08--0.06)$ & $(-0.25--0.21)$ \\
\hline \multirow[t]{2}{*}{ F Unempl-M Bor } & -0.02 & -0.05 \\
\hline & $(-0.07-0.03)$ & $(-0.14-0.04)$ \\
\hline \multirow[t]{2}{*}{ F Unempl-M WhC } & -0.01 & $-0.17^{* * *}$ \\
\hline & $(-0.03-0.01)$ & $(-0.21--0.13)$ \\
\hline \multirow[t]{2}{*}{ F Unempl—M PB } & $-0.05^{* *}$ & $-0.21^{* * *}$ \\
\hline & $(-0.09--0.01)$ & $(-0.26--0.16)$ \\
\hline \multirow[t]{2}{*}{ F Unempl-M WC } & $-0.10^{* * *}$ & $-0.25^{* * *}$ \\
\hline & $(-0.13--0.08)$ & $(-0.27--0.22)$ \\
\hline \multirow[t]{2}{*}{ Both unempl } & $-0.12^{* * *}$ & $-0.26^{* * *}$ \\
\hline & $(-0.15--0.09)$ & $(-0.28--0.24)$ \\
\hline \multirow[t]{2}{*}{ F Unempl-M Inact } & $-0.13^{* * *}$ & $-0.24^{* * *}$ \\
\hline & $(-0.15--0.11)$ & $(-0.26--0.22)$ \\
\hline \multirow[t]{2}{*}{ F Inact-M Bor } & -0.01 & -0.02 \\
\hline & $(-0.03-0.01)$ & $(-0.07-0.02)$ \\
\hline \multirow[t]{2}{*}{ F Inact-M WhC } & $-0.02^{* * *}$ & $-0.12^{* * *}$ \\
\hline & $(-0.03--0.01)$ & $(-0.15--0.10)$ \\
\hline \multirow[t]{2}{*}{ F Inact-M PB } & $-0.03^{* *}$ & $-0.19^{* * *}$ \\
\hline & $(-0.05--0.00)$ & $(-0.22--0.16)$ \\
\hline \multirow[t]{2}{*}{ F Inact-M WC } & $-0.11 * * *$ & $-0.23^{* * *}$ \\
\hline & $(-0.13--0.09)$ & $(-0.25--0.20)$ \\
\hline
\end{tabular}


Table 1 Beta coefficients (with 95\% c.i.) of control variables from Figs. 1 and 2 (model 4) (Continued)

\begin{tabular}{|c|c|c|}
\hline & $\begin{array}{l}\text { Enrolment } \\
\text { (M4) }\end{array}$ & $\begin{array}{l}\text { Academic } \\
(\mathrm{M} 4)\end{array}$ \\
\hline \multirow[t]{2}{*}{ F Inact-M Unempl } & $-0.14^{* * *}$ & $-0.27^{* * *}$ \\
\hline & $(-0.18--0.10)$ & $(-0.30--0.24)$ \\
\hline \multirow[t]{2}{*}{ Both Inact } & $-0.12^{* * *}$ & $-0.24^{* * *}$ \\
\hline & $(-0.13--0.10)$ & $(-0.26--0.22)$ \\
\hline \multicolumn{3}{|c|}{ Region of residence (ref. Piemonte) } \\
\hline \multirow[t]{2}{*}{ Valle d'Aosta } & 0.00 & $-0.07^{* * *}$ \\
\hline & $(-0.01-0.02)$ & $(-0.09--0.06)$ \\
\hline \multirow[t]{2}{*}{ Lombardia } & $-0.02^{* * *}$ & $-0.05^{* * *}$ \\
\hline & $(-0.02--0.01)$ & $(-0.06--0.04)$ \\
\hline \multirow[t]{2}{*}{ Trentino Alto Adige } & $-0.08^{* * *}$ & $-0.09^{* * *}$ \\
\hline & $(-0.09--0.07)$ & $(-0.10--0.08)$ \\
\hline \multirow[t]{2}{*}{ Veneto } & -0.01 & $-0.03^{* * *}$ \\
\hline & $(-0.02-0.00)$ & $(-0.05--0.02)$ \\
\hline \multirow[t]{2}{*}{ Friuli Venezia Giulia } & $0.03^{* * *}$ & $-0.02^{* * *}$ \\
\hline & $(0.01-0.04)$ & $(-0.04--0.01)$ \\
\hline \multirow[t]{2}{*}{ Liguria } & $0.02^{* * *}$ & $0.03^{* * *}$ \\
\hline & $(0.01-0.03)$ & $(0.02-0.05)$ \\
\hline \multirow[t]{2}{*}{ Emilia-Romagna } & $0.03^{* * *}$ & $-0.06^{* * *}$ \\
\hline & $(0.02-0.04)$ & $(-0.07--0.05)$ \\
\hline \multirow[t]{2}{*}{ Toscana } & $0.04^{* * *}$ & $-0.04^{* * *}$ \\
\hline & $(0.03-0.05)$ & $(-0.05--0.03)$ \\
\hline \multirow[t]{2}{*}{ Umbria } & $0.05^{* * *}$ & 0.01 \\
\hline & $(0.04-0.06)$ & $(-0.01-0.02)$ \\
\hline \multirow[t]{2}{*}{ Marche } & $0.04^{* * *}$ & $-0.02^{* *}$ \\
\hline & $(0.03-0.05)$ & $(-0.03--0.00)$ \\
\hline \multirow[t]{2}{*}{ Lazio } & $0.04^{* * *}$ & $0.05^{* * *}$ \\
\hline & $(0.03-0.04)$ & $(0.04-0.06)$ \\
\hline \multirow[t]{2}{*}{ Abruzzo } & $0.05^{* * *}$ & $0.03^{* * *}$ \\
\hline & $(0.04-0.06)$ & $(0.01-0.05)$ \\
\hline \multirow[t]{2}{*}{ Molise } & $0.08^{* * *}$ & $0.05^{* * *}$ \\
\hline & $(0.07-0.09)$ & $(0.04-0.07)$ \\
\hline \multirow[t]{2}{*}{ Campania } & $0.03^{* * *}$ & $0.07^{* * *}$ \\
\hline & $(0.02-0.04)$ & $(0.06-0.08)$ \\
\hline \multirow[t]{2}{*}{ Puglia } & $0.04^{* * *}$ & $0.06^{* * *}$ \\
\hline & $(0.03-0.05)$ & $(0.05-0.07)$ \\
\hline \multirow[t]{2}{*}{ Basilicata } & $0.08^{* * *}$ & $0.06^{* * *}$ \\
\hline & $(0.07-0.09)$ & $(0.04-0.07)$ \\
\hline \multirow[t]{2}{*}{ Calabria } & $0.06^{* * *}$ & $0.06^{* * *}$ \\
\hline & $(0.05-0.07)$ & $(0.05-0.07)$ \\
\hline \multirow[t]{2}{*}{ Sicilia } & $0.01^{* * *}$ & $0.03^{* * *}$ \\
\hline & $(0.00-0.02)$ & $(0.02-0.04)$ \\
\hline \multirow[t]{2}{*}{ Sardegna } & $0.04^{* * *}$ & $0.08^{* * *}$ \\
\hline & $(0.03-0.05)$ & $(0.06-0.09)$ \\
\hline
\end{tabular}


Table 1 Beta coefficients (with 95\% c.i.) of control variables from Figs. 1 and 2 (model 4) (Continued)

\begin{tabular}{|c|c|c|}
\hline & $\begin{array}{l}\text { Enrolment } \\
\text { (M4) }\end{array}$ & $\begin{array}{l}\text { Academic } \\
\text { (M4) }\end{array}$ \\
\hline \multicolumn{3}{|l|}{ Birth order (ref. Only child) } \\
\hline \multirow[t]{2}{*}{ First born } & $0.02^{* * *}$ & $0.02^{* * *}$ \\
\hline & $(0.01-0.02)$ & $(0.01-0.02)$ \\
\hline \multirow[t]{2}{*}{ Second born } & $-0.02^{* * *}$ & $-0.05^{* * *}$ \\
\hline & $(-0.03--0.02)$ & $(-0.06--0.05)$ \\
\hline \multirow[t]{2}{*}{ Third born or more } & $-0.04^{* * *}$ & $-0.07^{* * *}$ \\
\hline & $(-0.05--0.03)$ & $(-0.09--0.06)$ \\
\hline \multicolumn{3}{|l|}{ Family size (< 3 children) } \\
\hline \multirow[t]{2}{*}{3 children or more } & $-0.04^{* * *}$ & $-0.02^{* * *}$ \\
\hline & $(-0.05--0.04)$ & $(-0.03--0.02)$ \\
\hline \multicolumn{3}{|l|}{ Age (ref. 15) } \\
\hline \multirow[t]{2}{*}{16} & $-0.01^{* * *}$ & -0.00 \\
\hline & $(-0.01--0.00)$ & $(-0.01-0.00)$ \\
\hline \multirow[t]{2}{*}{17} & $-0.03^{* * *}$ & $-0.01^{* * *}$ \\
\hline & $(-0.03--0.02)$ & $(-0.02--0.00)$ \\
\hline \multirow[t]{2}{*}{18} & $-0.05^{* * *}$ & $-0.02 * * *$ \\
\hline & $(-0.06--0.05)$ & $(-0.02--0.01)$ \\
\hline \multirow[t]{2}{*}{ Born abroad } & $-0.14^{* * *}$ & $-0.09^{* * *}$ \\
\hline & $(-0.15--0.13)$ & $(-0.09--0.08)$ \\
\hline \multirow[t]{2}{*}{ Female } & $0.04^{* * *}$ & $0.04^{* * *}$ \\
\hline & $(0.04-0.05)$ & $(0.04-0.05)$ \\
\hline \multirow[t]{2}{*}{ Constant } & $0.63^{* * *}$ & $0.25^{* * *}$ \\
\hline & $(0.59-0.66)$ & $(0.22-0.28)$ \\
\hline Observations & 213,538 & 213,538 \\
\hline$R$-squared & 0.13 & 0.23 \\
\hline
\end{tabular}

Notes: Dummies for trimester of interview are not shown

$*^{* * *} p<0.01$

$* * p<0.05$

${ }^{*} p<0.1$

\section{Abbreviations}

DDT: Diverging destinies thesis; EGP: Erikson-Goldthorpe-Portocarero class scheme; IEO: Inequality of educational outcomes; ILFS: Italian labour force survey; ISTAT: Italian National Institute of Statistics; LPM: Linear probability model; SES: Socioeconomic status

\section{Acknowledgements}

Raffaele Guetto acknowledges the financial support provided by the European Union's Horizon 2020 research and innovation programme/ERC Grant Agreement No 725961 (EU-FER project "Economic Uncertainty and Fertility in Europe", Pl: Daniele Vignoli).

\section{Authors' contributions}

The author(s) read and approved the final manuscript.

Funding

Not applicable.

\section{Availability of data and materials}

Not applicable.

\section{Competing interests}

The authors declare that they have no competing interests. 


\section{Author details}

${ }^{1}$ Department of Social and Political Sciences, University of Milan, via Conservatorio 7, 20122 Milan, Italy. ${ }^{2}$ Department of Statistics, Computer Science, Applications, University of Florence, viale Morgagni 59, 50134 Florence, Italy.

Received: 18 February 2020 Accepted: 7 May 2020

Published online: 27 May 2020

\section{References}

Addo, F. R., Sassler, S., \& Williams, K. (2016). Reexamining the association of maternal age and marital status at first birth with youth educational attainment. Journal of Marriage and Family, 78, 1252-1268.

Amato, P. R., \& Anthony, C. J. (2014). Estimating the effects of parental divorce and death with fixed effects models. Journal of Marriage and Family, 76, 370-386.

Atkinson, M. P., \& Glass, B. L. (1985). Marital age heterogamy and homogamy, 1900 to 1980. Journal of Marriage and the Family, 685-691.

Ballarino, G., \& Panichella, N. (2016). Social stratification, secondary school tracking and university enrolment in Italy. Contemporary Social Science, 11(2-3), 169-182.

Ballarino, G., \& Schadee, H. (2010). Allocation and distribution: A discussion of the educational transition model, with reference to the Italian case. Research in Social Stratification and Mobility, 28, 45-58.

Barbieri, M., Hertrich, V., \& Grieve, M. (2005). Age difference between spouses and contraceptive practice in sub-Saharan Africa. Population, 60(5), 617-654.

Barclay, K., \& Myrskylä, M. (2016). Advanced maternal age and offspring outcomes: Reproductive aging and counterbalancing period trends. Population and Development Review, 42(1), 69-94.

Bernardi, F. (2014). Compensatory advantage as a mechanism of educational inequality: A regression discontinuity based on month of birth. Sociology of Education, 87(2), 74-88.

Bernardi, F., \& Boertien, D. (2016). Understanding heterogeneity in the effects of parental separation on educational attainment in Britain: Do children from lower educational backgrounds have less to lose? European Sociological Review, 32, 807-819.

Bernardi, F., \& Boertien, D. (2017). Non-intact families and diverging educational destinies: A decomposition analysis for Germany, Italy, the United Kingdom and the United States. Social Science Research, 63, 181-191.

Bernardi, F., \& Comolli, C. L. (2019). Parental separation and children's educational attainment: Heterogeneity and rare and common educational outcomes. ZfF-Zeitschrift für Familienforschung/Journal of Family Research, 31(1).

Bernardi, F., \& Radl, J. (2014). The long-term consequences of parental divorce for children's educational attainment. Demographic Research, 30, 1653-1680.

Bewley, S., Davies, M., \& Braude, P. (2005). Which career first? Best age for childbearing remains 20-35. British Medical Journal, $331,588-589$

Bhrolcháin, N. M., \& Beaujouan, É. (2012). Fertility postponement is largely due to rising educational enrolment. Population Studies, 66(3), 311-327.

Billari, F. C., Liefbroer, A. C., \& Philipov, D. (2006). The postponement of childbearing in Europe: Driving forces and implications. Vienna Yearbook of Population Research, 1-17.

Billari, F. C., \& Rosina, A. (2004). Italian "latest-late" transition to adulthood: An exploration of its consequences on fertility. Genus, 60(1), 71-87.

Björklund, A., \& Salvanes, K. G. (2011). Education and family background: Mechanisms and policies. In E. A. Hanushek, S. Machin, \& L. Woessmann (Eds.), Handbook of the economics of education (Vol. 3, pp. 201-247). Amsterdam, Netherlands: North Holland.

Blake, J. (1989). Family size and achievement (Vol. 3). Berkeley and Los Angeles: University of California Press.

Brand, J. E., Moore, R., Song, X., \& Xie, Y. (2019). Parental divorce is not uniformly disruptive to children's educational attainment. Proceedings of the National Academy of Sciences, 116(15), 7266-7271.

Cain, M. (1993). Patriarchal structure and demographic change. In N. Federici, K. O. Mason, \& S. Sogner (Eds.), Women's position and demographic change (pp. 43-60). Oxford, UK: Clarendon Press.

Cantalini, S. (2020). Famiglia e disuguaglianza: Matrimonio, fecondità e posizione sociale nell'talia contemporanea. Milano: Franco Angeli.

Checchi, D., \& Flabbi, L. (2007). Intergenerational mobility and schooling decisions in Germany and Italy: The impact of secondary school tracks. IZA Discussion Paper No. 2876.

Contini, D., \& Scagni, A. (2011). Inequality of opportunity in secondary school enrolment in Italy, Germany and the Netherlands. Quality and Quantity, 45, 441-464.

Cooksey, E. C. (1997). Consequences of young mothers' marital histories for children's cognitive development. Journal of Marriage and the Family, 245-261.

Dalla Zuanna, G. (2004). Few children in strong families. Values and low fertility in Italy. Genus, 60(1), 39-70.

De Sandre, P., Ongaro, F., Rettaroli, R., \& Salvini, S. (1997). Matrimonio e figli: tra rinvio e rinuncia. Bologna: II Mulino.

Durkin, M. S., Maenner, M. J., Newschaffer, C. J., Lee, L.-C., Cunniff, C. M., Daniels, J. L., Kirby, R. S., Leavitt, L., Miller, L., Zahorodny, W., \& Schieve, L. A. (2008). Advanced parental age and the risk of autism spectrum disorder. American Journal of Epidemiology, 168(11), 1268-1276.

Erikson, R., Goldthorpe, J. H., \& Portocarero, L. (1979). Intergenerational class mobility in three western European societies: England, France and Sweden. The British Journal of Sociology, 30, 415-441.

Fall, C. H., Sachdev, H. S., Osmond, C., Restrepo-Mendez, M. C., Victora, C., Martorell, R., et al. (2015). Association between maternal age at childbirth and child and adult outcomes in the offspring: A prospective study in five low-income and middle-income countries (COHORTS collaboration). The Lancet Global Health, 3(7), 366-377.

Ferrari, G., \& Zuanna, G. D. (2010). Siblings and human capital: A comparison between Italy and France. Demographic Research, 23, 587-614.

Fishman, S. H., \& Min, S. (2018). Maternal age and offspring's educational attainment. Journal of Marriage and Family, 80(4), 853-870.

Fisk Green, R., Devine, O., Crider, K. S., Olney, R. S., Archer, N., Olshan, A. F., ... \& Study, T. N. B. D. P. (2010). Association of paternal age and risk for major congenital anomalies from the National Birth Defects Prevention Study, 1997 to 2004. Annals of epidemiology, 20(3), 241-249.

Francesconi, M. (2008). Adult outcomes for children of teenage mothers. Scandinavian Journal of Economics, 110(1), 93-117. 
Geronimus, A. T., Korenman, S., \& Hillemeier, M. M. (1994). Does young maternal age adversely affect child development? Evidence from cousin comparisons in the United States. Population and Development Review, 20, 585-608.

Goisis, A., \& Sigle-Rushton, W. (2014). Childbearing postponement and child well-being: A complex and varied relationship? Demography, 51(5), 1821-1841.

Grätz, M. (2014). When growing up without a parent does not hurt: Parental separation and the compensatory effect of social origin. European Sociological Review, 31, 546-557.

Guetto, R., Luijkx, R., \& Scherer, S. (2015). Religiosity, gender attitudes and women's labour market participation and fertility decisions in Europe. Acta Sociologica, 58(2), 155-172.

Guetto, R., \& Panichella, N. (2019). Family arrangements and children's educational outcomes: Heterogeneous penalties in upper-secondary school. Demographic Research, 40, 1015-1046.

Guetto, R., \& Vergolini, L. (2017). Educational expansion without equalization: A reappraisal of the 'Effectively Maintained Inequality' hypothesis in children's choice of the upper secondary track. European Societies, 19(1), 1-27.

Hemminki, K., \& Kyyrönen, P. (1999). Parental age and risk of sporadic and familial cancer in offspring: Implications for germ cell mutagenesis. Epidemiology, 747-751.

Hofferth, S. L., \& Reid, L. (2002). Early childbearing and children's achievement and behavior over time. Perspectives on Sexual and Reproductive Health, 41-49.

Ichou, M., \& Vallet, L.-A. (2011). Do all roads lead to inequality? Trends in French upper secondary school analysed with four longitudinal surveys. Oxford Review of Education, 37, 167-194.

Italian Institute of Statistics (ISTAT). (2016). I percorsi di studio e lavoro dei diplomati e dei laureati. Statistiche: Report.

Jacobsson, B., Ladfors, L., \& Milsom, I. (2004). Advanced maternal age and adverse perinatal outcome. Obstetrics \& Gynecology, 104(4), 727-733.

Jensen, R., \& Thornton, R. (2003). Early female marriage in the developing world. Gender \& Development, 11(2), 9-19.

Johnson, K. J., Carozza, S. E., Chow, E. J., Fox, E. E., Horel, S., McLaughlin, C. C., Mueller, B. A., Puumala, S. E., Reynolds, P., Von Behren, J., \& Spector, L. G. (2009). Parental age and risk of childhood cancer: A pooled analysis. Epidemiology, 20(4), 475-483.

Kemkes-Grottenthaler, A. (2004). Parental effects on offspring longevity-evidence from 17th to 19th century reproductive histories. Annals of human biology, 31(2), 139-158.

Kohler, H.P., Billari, F. C., \& Ortega, J. A. (2002). The emergence of lowest-low fertility in Europe during the1990s. Population and Development Review, 28(4), 641-680.

Lehrer, E. L. (2008). Age at marriage and marital instability: Revisiting the Becker-Landes-Michael hypothesis. Journal of Population Economics, $21(2), 463-484$.

Levine, J. A., Emery, C. R., \& Pollack, H. (2007). The well-being of children born to teen mothers. Journal of Marriage and Family, 69(1), 105-122.

Levine, J. A., Pollack, H., \& Comfort, M. E. (2001). Academic and behavioral outcomes among the children of young mothers. Journal of Marriage and Family, 63, 355-369.

Lopez-Castroman, J., Gómez, D. D., Belloso, J. J. C., Fernandez-Navarro, P., Perez-Rodriguez, M. M., Villamor, I. B., et al. (2010). Differences in maternal and paternal age between schizophrenia and other psychiatric disorders. Schizophrenia research, 116(2-3), 184-190.

Mare, R. D., \& Tzeng, M. S. (1989). Fathers' ages and the social stratification of sons. American Journal of Sociology, 95(1), 108-131.

Martin, S. P. (2000). Diverging fertility among US women who delay childbearing past age 30. Demography, 37(4), 523-533.

McLanahan, S. (2004). Diverging destinies: How children are faring under the second demographic transition. Demography, $41,607-627$.

Mood, C. (2010). Logistic regression: Why we cannot do what we think we can do, and what we can do about it. European Sociological Review, 26(1), 67-82.

Myrskylä, M., Barclay, K., \& Goisis, A. (2017). Advantages of later motherhood. Der Gynäkologe, 50(10), 767-772.

Myrskylä, M., Silventoinen, K., Tynelius, P., \& Rasmussen, F. (2013). Is later better or worse? Advanced parental age and offspring IQ among half a million Swedish men. American Journal of Epidemiology, 177(7), 649-655.

Ní Bhrolcháin, M. (2005). The age difference at marriage in England and Wales: A century of patterns and trends. Population trends, 120, 7-14.

Oláh, L. S. (2015). Changing families in the European Union: Trends and policy implications. Families and societies working paper series, N. 44.

Panichella, N., \& Triventi, M. (2014). Social inequalities in the choice of secondary school: Long-term trends during educational expansion and reforms in Italy. European Societies, 16(5), 666-693.

Paulhus, D. L., Trapnell, P. D., \& Chen, D. (1999). Birth order effects on personality and achievement within families. Psychological Science, 10(6), 482-488.

Rocca, W. A., Van Duijn, C. M., Clayton, D., Chandra, V., Fratiglioni, L., Graves, A. B., ... \& Mortimer, J. A. (1991). Maternal age and Alzheimer's disease: A collaborative re-analysis of case-control studies. International Journal of Epidemiology, 20(Supplement_2), S21-S27.

Salvini, S. (2004). Low Italian fertility: The bonaccia of the Antilles? Genus, 60(1), 19-38.

Schneider, S. L., \& Tieben, N. (2011). A healthy sorting machine? Social inequality in the transition to upper secondary education in Germany. Oxford Review of Education, 37(2), 139-166.

Shehan, C. L., Berardo, F. M., Vera, H., \& Carley, S. M. (1991). Women in age-discrepant marriages. Journal of Family 1ssues, 12(3), 291-305.

Singh, S., Darroch, J. E., \& Frost, J. J. (2001). Socioeconomic disadvantage and adolescent women's sexual and reproductive behavior: The case of five developed countries. Family planning perspectives, 33(6), 251-289.

Van de Putte, B., Van Poppel, F., Vanassche, S., Sanchez, M., Jidkova, S., Eeckhaut, M., et al. (2009). The rise of age homogamy in 19th century western Europe. Journal of Marriage and Family, 71(5), 1234-1253.

Yip, B. H., Pawitan, Y., \& Czene, K. (2006). Parental age and risk of childhood cancers: A population-based cohort study from Sweden. International Journal of Epidemiology, 35(6), 1495-1503.

\section{Publisher's Note}

Springer Nature remains neutral with regard to jurisdictional claims in published maps and institutional affiliations. 